\title{
BETONARME BİNALARIN WEB TABANLI HIZLI DEĞERLENDİRİLMESI
}

\author{
Ercan IŞIK* \\ Mehmet Fatih IŞIK ${ }^{* * *}$

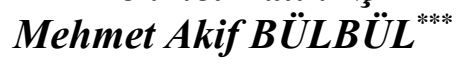

Alınma: 18.08.2016; düzeltme: 09.03.2018; kabul: 13.03.2018

Öz: Yapılarda hızlı değerlendirme yöntemleri kullanılarak yapıların risk öncelliklerine karar verilebilmektedir. Bu çalışmada, Çevre ve Şehircilik Bakanlığı tarafından yayımlanan betonarme binalar için kullanılan birinci aşama değerlendirme yönteminin akıllı telefon ve tabletlerde kullanılması amacı ile PHP (Hypertext Preprocessor) tabanlı web uygulaması gerçekleştirilmiştir. Çalışmada dikkate alınan hızlı değerlendirme yönteminde yer alan tüm parametreler için veri girişi yapılabilecek şekilde veri tabanı oluşturulmuş̧ur. İncelenen binalara ait görsellerde bu veri tabanına kaydedilmektedir. Bu çalışma ile 1-7 katlı betonarme mevcut yapılar için risk öncelik kartı oluşturulmuştur. Yerel yönetimler, ilgili kamu kurum ve kuruluşları ile yapı sahipleri, yapıların risk önceliğine akıllı telefon veya tablet kullanarak ulaşılabilme imkanına sahip olmaktadır. Çalışma ile binalara ait bilgiler web sunucu üzerinden MYSQL dilinde yazılan bir veri tabanına aktarılmışıı. Ayrıca binalara yapıştıılan QR (Quick Response) uygulaması sayesinde günümüz iletişim teknolojisinin vazgeçilmez elemanları olan akıllı telefon ve tabletler ile betonarme binaların risk önceliklerine erişim son derece hızlı ve kolay bir duruma getirilmiştir. Bu yöntem ile klasik değerlendirme için kullanılan yöntemler yerine daha hızlı ve kolay bir yöntem ortaya konulmuştur.

Anahtar Kelimeler: Depremsellik, Hızlı değerlendirme, Web tabanlı, betonarme bina

\section{Web-Based Rapid Evaluation of Reinforced Concrete Building}

\begin{abstract}
Risk priorities of structures can be decided by using rapid assessment methods in the structures. In this study, to use the first phase assessment method in Smartphones and tablets, PHP (Hypertext Preprocessor) based web application was conducted. The first phase assessment method is used for the reinforced concrete buildings and was issued by the Ministry of Environment and Urban Planning. For the data input, a database has been created for all the considered parameters used in the rapid assessment method in the study. Visuals of the examined buildings are also recorded to this database. By this study, the risk priority card for 1-7 story reinforced concrete structures has been established. Local governments, relevant government agencies and organizations, and building owners are having the opportunity to reach to the risk priority of the structures using a Smartphone or tablet. Data of the buildings was transferred into a database written by the MySQL language via web server. Also, QR (Quick Response) application that affixed to the buildings provide an extremely fast and easy access to the risk priority of the reinforced concrete structures thanks to the today's indispensable technology elements that are smart phones and tablets. This method has provided a faster and easier method instead of conventional methods used for the evaluation.
\end{abstract}

Keywords: Seismicity, Rapid assessment, web-based, reinforced concrete building

\footnotetext{
* Bitlis Eren Üniversitesi, Mühendislik-Mimarlık Fakültesi, İnşaat Müh. Bölümü, 13100, BİTLİS

***Hitit Üniversitesi, Mühendislik Fakültesi, Elektrik Müh. Bölümü, 19030, ÇORUM

****Hitit Üniversitesi, Teknik Bilimler Meslek Yüksekokulu, Bilgisayar Programcıllı̆ı, 19030, ÇORUM

İletişim Yazarı: Ercan IŞIK (eisik@beu.edu.tr)
} 


\section{GİRIŞ}

Özellikle son yıllarda yaşanan yıkıcı depremler ve bu depremler sonucunda oluşan büyük çaplı can ve mal kayıpları deprem konusunda yapılan çalışmaları, araştırmaları ve alınacak önlemlerin önemini gündeme getirmiştir. Kentlerin giderek artan yap1 stokunun belirlenmesi, analiz edilmesi ve yapılar ile ilgili tüm bilgilerin tespit edilmesi ve yönetilmesi mekansal planlama ve kentsel dönüşüm açısından önemlidir.

Deprem performans1, belirli bir deprem etkisi altında bir binada oluşabilecek hasarların düzeyi ve dağılımına bağlı olarak belirlenen yapı güvenliği olarak tanımlanmaktadır (Sucuoğlu, 2007). Yapıların deprem güvenliğinin belirlenmesinde esas amaç mevcut yapılarda gerekli inceleme ve hesaplarının olası bir depremden önce yapılarak mevcut yapı stoku hakkında doğru kararlar verilmesini sağlamaktır. Mevcut yapı stokunun çok olması, yapılar üzerindeki değerlendirmeyi zaman, nitelikli eleman yetersizliği ve ekonomik açıdan güçleştirmektedir. Herhangi bir yapının deprem güvenliğinin detaylı olarak incelenmesi bile günler boyunca sürmektedir. Dolaysıyla mevcut her yapının detaylı olarak incelenmesi mümkün görünmemektedir. Bu bağlamda yapıların daha hızlı ve doğru sonuçlar verecek yöntemler kullanılarak doğru sonuçlara ulaşılabilmektedir (Işık, 2015). Bu yöntemler genel olarak birinci aşama değerlendirme yöntemi olarak adlandırılmaktadır. Bu yöntemler kullanılarak risk önceliği olan binalar belirlenebilmektedir. Bu da, detaylı analize tabi tutulacak bina sayısında büyük oranda azaltma meydana getirecektir (Işık, 2013).

Bu çalışmada, 2013 yılında yürürlüğe giren Afet Riski Altındaki Alanların Dönüştürülmesi Hakkında Kanunun Uygulama Yönetmeliğinde yer alan riskli yapıların tespit edilmesine ilişkin esaslar kısmında bulunan birinci aşama değerlendirme yöntemi kullanılarak mevcut 1-7 katlı betonarme yapıların web tabanlı hızlı değerlendirilmesini içermektedir.

Yapılar ile ilgili özelliklerin arşivlenmesi ve istenildiğinde bu bilgilere kolaylıkla ulaşılabilmesi yerel yönetimler, ilgili kamu kurum ve kuruluşları ile yapı sahipleri açısından önem arz etmektedir. Yapı ile ilgili bir takım bilgi ve belgeler mevcut olsa da çoğu zaman bunlara ulaşmak bilgilerin farklı kurumlarda olmasından dolayı bir hayli zor olmaktadır. $\mathrm{Bu}$ bağlamda, bu bilgilerin ortak bir veri tabanında tutulması, istenildiğinde hızlı ve kolay erişilebilir olması Türkiye'de hem ilgili kamu kurumları hem de yapı sahipleri için uygulanabilir bir çözüm olarak görülmektedir.

Hem inşaat hem de bilişim sektörünün gelişmesi, yapıların değerlendirilmesi hızlı ve kolay hale gelmiş, gereksiz kırtasiyeciliğin önüne geçilmiştir. Web tabanı uygulaması günümüz teknolojik ortamında birçok sektörde yaygın olarak kullanılmaktadır. Bu çalışmada, mevcut 1-7 katlı betonarme yapıların değerlendirilmesi için web sayfası oluşturulmuş ve bu binaların risk öncelik puanları elde edilmiştir. Mevcut yapılar için geçerli parametrik veriler elektronik bir ortama taşınarak kullanıcıların bu verileri anlamlı olarak kullanmaları amaçlanmıştır. $\mathrm{Bu}$ amaçla Bitlis ili, Tatvan ilçesinde bulunan 13 adet betonarme bina veri tabanına eklenmiş ve değerlendirilmesi gerçekleştirilmiştir.

\section{MATERYAL VE METOT}

Yerel yönetimler, kentsel ve kırsal alanda sundukları hizmetlerin zaman içerisinde artmasıyla, ekonomik olarak kaynak artışına gitmek zorunda kalmışlardır. Buna paralel olarak büyük kitlelerin yaşadığı mekanların yönetilmesinde gelişen bilgi teknolojileri kullanmak bir zorunluluk haline gelmiştir.

Türkiye'de yerel yönetimler, kitlelerin yaşadığı mekanlara ait bilgi arşivlemesini yaparken bağımsız olarak çalışmaktadırlar. Yerel yönetimler tarafından toplanan veriler arasında sağlıklı ilişki kurulamadığı için bu bilgilere ihtiyaç duyan diğer kullanıcılar erişim noktasında ciddi sıkıntılar yaşamaktadır. Bu sıkıntılar insan kitlelerinin yaşadığı mekanlara ait doğru bilgiye erişim noktasında da kendini göstermektedir. 
Bilgisayar, akıllı cihazlar ve internet teknolojisindeki gelişmeler sonucunda yerel yönetimler de kendi hizmet alanları için kullandıkları konumsal verileri bilgisayar ortamında toplamaya, depolamaya, işlemeye ve analizler sonucu yeni bilgiler üretmeye başlamışlardır.

Bina değerlendirme ve izleme sistemlerinde bilgi teknolojilerinden daha fazla yararlanma isteği gün geçtikçe artış göstermektedir. Buna paralel olarak, tablet ve akıllı telefonlar gibi mobil aygıtların yaygınlaşmasında, küçük bir bilgisayar sistemi haline gelmesi, kablosuz ve kolay taşınabilir olmasının yanında çok hızlı çalışması ve geniş hafıza kapasitesinin bulunması bu aygıtların kullanımını artırmıştır. $\mathrm{Bu}$ unsurlar mobil aygıtların çevresel kontrol, sağlık hizmetlerinin izlenebilmesi, güvenlik, taşıma ve otomasyon gibi birçok uygulamada kullanılmasını zorunlu hale getirmiştir (Gong ve diğ.,2013; Delgado ve diğ., 2013; Sallabi ve diğ., 2011; Qin ve diğ., 2014; Lehmann ve diğ., 2012; Brooders ve diğ., 2013; Lee ve Chung,2012; Ishigaki ve diğ., 2013; Lee ve diğ.,2013).

Türkiye'de yap1 stokunun miktarı düşünüldüğünde yapılar ile ilgili parametrik verilerin doğru bilinip bu verilere kolay ve hızlı ulaşılabilmesi önemlidir. Yapıların detaylı olarak incelenmesi hem ekonomik olarak hem de teknik eleman açısından oldukça zordur. $\mathrm{Bu}$ bağlamda yapıların önceliklerinin belirlenmesi ile ilgili literatürde hızlı tarama yöntemleri mevcuttur. Hızlı tarama yöntemlerinde amaç yapılar için risk önceliğinin belirlenerek yapılar için doğru kararlar verilmesini sağlamaktır. Bu yöntemler ile bina içine girilmeden veya kısmen de bina içine girilerek, yöntemin verdiği parametrelerin toplanması sonucu yap1 performans puanı hesaplanmakta ve karşılaştırma sonucu binanın risk öncelliğine karar verilebilmektedir. Türkiye Cumhuriyeti, Çevre ve Şehircilik Bakanlığı tarafından yayınlanan kanun kapsamında belirli alanlarda önceliklerin ve riskli olabilecek binaların bölgesel dağılımının belirlenmesi amacıyla; bina özelliklerini ve deprem tehlikesini göz önüne alan birinci aşama değerlendirme yöntemleri kullanılabilmektedir (RBTE, 2013).

\section{BETONARME BİNALAR İÇİN HIZLI DEĞERLENDİRME YÖNTEMİ}

Olası bir depreme, en iyi şekilde hazırlanmak için depremin hangi bölgeleri, hangi tipteki yapıları en çok etkileyeceği ve depremin olası sonuçlarını deprem olmadan önce tahmin edebilmek önemlidir. Deprem risklerinin değerlendirilmesi aşamasında ve depremlerin neden olabileceği zararların tahmininde riskli yapıların tespit edilmesi önem arz etmektedir. Meydana gelebilecek olası depremlerde can ve mal kayıplarının en aza indirgenmesi için mevcut yapı stokunun deprem performanslarının bilinmesi önem arz etmektedir. Ancak mevcut yap1 stokunun çok fazla olması yapıların değerlendirilme sürecini zaman ve maliyet açısından ekonomik kılmamaktadır. Dolayısıyla mevcut yapı stoku üzerinde hızlı ve doğru değerlendirme yöntemlerini kullanmak bir çözüm olarak görülmektedir (Işık, 2013).

Yapıların deprem güvenliğinin belirlenmesinde esas amaç, mevcut yapılarda gerekli inceleme ve hesapların olası bir depremden önce yapılarak ve yetersiz görülen yapıların depremde hedeflenen performans seviyesine yükseltilmesi için uygulanacak iyileştirme işlemlerine karar verilmesidir. Deprem tehlikesi altında olan kentsel yerleşimlerde yeterli deprem güvenliğine sahip olmayan pek çok yapı olduğu bilinmektedir.

Yap1 hasarlarının, yapının özelliklerine göre değiştiği çok iyi bilinen bir gerçektir. Ancak, bu özelliklerin ortaya konmas1, siniflandırılması sonucunda elde edilen verilerin değerlendirilmesi koşulu ile gerçekleşebilmektedir. Bu bağlamda riskli binaların tespit edilmesi önem arz etmektedir.

Bakanlık tarafından yayınlanan kanun kapsamında belirli alanlarda önceliklerin ve riskli olabilecek binaların bölgesel dağılımının belirlenmesi amacıyla; bina özelliklerini ve deprem tehlikesini göz önüne alan birinci aşama değerlendirme yöntemleri kullanılabilir. Yapılacak sıralamanın daha hassas olması istenirse, ikinci aşama değerlendirme yöntemleri de kullanılabilir. 
Düşük riskli çıkan binaların deprem yönetmeliğine uygun olup olmadığı kesin bir dille söylenemez. Yukarıda belirtildiği gibi bu sadece birinci aşama değerlendirmedir. Dolayısıyla kesin sonuçlar ancak kesin analiz yöntemleri sonucunda ortaya çıkacaktır. Bu yöntem sadece ikinci aşama değerlendirme yönteminde incelecek binaların önceliğinin belirlenmesi amac1 taşımaktadır.

$\mathrm{Bu}$ yöntem 1-7 katlı mevcut betonarme binalar için kullanılabilir. Yöntemin kullanılabilmesi için gerekli olan parametreler aşağıda verilmektedir:

- Taşıyıcı sistem türü

- Kat adedi

- Mevcut durum ve görünen kalite

- Yumuşak kat/zayıf kat:

- Düşeyde düzensizlik

- Ağır çıkmalar

- Planda düzensizlik/Burulma etkisi

- Kisa kolon etkisi

- Yapı nizamı/Çarpışma etkisi

- Tepe/yamaç etkisi

- Deprem tehlikesi ve zemin sinifi

Deprem etkisindeki betonarme binaların değerlendirme ve izlenmesine ait parametrelerin elektronik ortamda bulunan veri tabanına kayıt edilebilmesi için oluşturulacak olan veri alanların belirlenmesinde Tablo 1 kullanılmıştır. Tablo 1'e göre sisteme veri girişi yapacak olan sistem yöneticisi, istenilen alanları doldurarak binaya ait verileri web tabanlı oluşturulan veri tabanı sayesinde sisteme yükleyebilmektedir. Bu durum ile ilgili yapılacak işlemler Bölüm 4'te detaylı olarak açıklanmıştır.

Tablo 1. İncelenen bina ait girdiler

\begin{tabular}{|l|l|l|l|}
\hline İl & & Mevcut durum ve kalite & \\
\hline İlçe & & Düşeyde süreksizlik & \\
\hline Mahalle & & Planda düzensizlik & \\
\hline Sokak/Cadde & & Yapı Nizamı & \\
\hline Bina Kapı No & & Yumuşak/zayıf kat & \\
\hline Ada & & Ağır çıkmalar & \\
\hline Parsel & & Kisa kolon varlı̆̆ & \\
\hline Enlem & Tepe - yamaç etkisi & \\
\hline Boylam & Taşıyıc Sitem Türü & \\
\hline Yüzölçümü (m2) & & Yapı Kat adedi & \\
\hline Gece nüfusu & & Zemin sinıfi & \\
\hline Gündüz nüfüsu & & Deprem Bölgesi & \\
\hline Niteliği & & Bina yapım yılı & \\
\hline
\end{tabular}

Yapı değerlendirilmesi yapılırken öncellikle yapının bulunduğu bölgenin depremselliği ve yapının yapıldığı zemin türüne göre tehlike bölgesi belirlenmelidir. Deprem bölgesi ve zemin durumuna göre tehlike bölgeleri Tablo 2'de verilmiştir. 
Tablo 2. DBYBHY'e göre belirlenen deprem bölgeleri (DBYBHY,2007)

\begin{tabular}{|c|c|c|}
\hline \multirow{2}{*}{ Tehlike bölgesi } & $\begin{array}{c}\text { DBYBHY'e göre deprem } \\
\text { bölgesi }\end{array}$ & $\begin{array}{c}\text { DBYBHY'e göre zemin } \\
\text { sinifi }\end{array}$ \\
\hline I & 1 & $\mathrm{Z} 3 / \mathrm{Z} 4$ \\
\hline \multirow{2}{*}{ II } & 1 & $\mathrm{Z} 1 / \mathrm{Z} 2$ \\
\cline { 2 - 3 } & 2 & $\mathrm{Z} 3 / \mathrm{Z} 4$ \\
\hline \multirow{2}{*}{ III } & 2 & $\mathrm{Z} 1 / \mathrm{Z} 2$ \\
\cline { 2 - 3 } & 3 & $\mathrm{Z} 3 / \mathrm{Z} 4$ \\
\hline \multirow{2}{*}{ IV } & 3 & $\mathrm{Z} 1 / \mathrm{Z} 2$ \\
\cline { 2 - 3 } & 4 & Tüm zeminler \\
\hline
\end{tabular}

Taşıyıcı sistem türünün etkisi olumlu puan olarak dikkate alınacaktır. Betonarme çerçeve (BAÇ) sistemine sahip binalar için herhangi bir ilave puan verilmeyip, taşıyıcı sistemi betonarme çerçeve ve perde (BAÇP) olan binalara Tablo 1 kullanılarak olumlu parametre puanı (OP) verilecektir. Tablo 3'te taban ve yapısal puanın nasıl alınacağı tarif edilmektedir.

Tablo 3: Taban ve yapısal sistem puanı tablosu (RBTE,2013)

\begin{tabular}{|c|c|c|c|c|c|c|}
\hline \multirow{4}{*}{$\begin{array}{l}\text { Toplam } \\
\text { kat } \\
\text { sayis1 }\end{array}$} & & & & & \multirow{2}{*}{\multicolumn{2}{|c|}{$\begin{array}{l}\text { Yapisal sistem puanı } \\
\text { (YSP) } \\
\text { Yapisal sistem }\end{array}$}} \\
\hline & \multirow{2}{*}{\multicolumn{4}{|c|}{$\frac{\text { Taban puanı }}{\text { Tehlike bölgesi }}$}} & & \\
\hline & & & & & & \\
\hline & I & II & III & IV & BAÇ & BAÇP \\
\hline 1 ve 2 & 90 & 120 & 160 & 195 & 0 & 100 \\
\hline 3 & 80 & 100 & 140 & 170 & 0 & 85 \\
\hline 4 & 70 & 90 & 130 & 160 & 0 & 75 \\
\hline 5 & 60 & 80 & 110 & 135 & 0 & 65 \\
\hline 6 ve 7 & 50 & 65 & 90 & 110 & 0 & 55 \\
\hline
\end{tabular}

Görünen kalite dışındaki tüm olumsuzluk parametreleri için "var" veya "yok" şeklinde tespitler yapılacaktır. Bu tespitlere karşl1ık gelen olumsuzluk parametre değerleri $\left(\mathrm{O}_{\mathrm{i}}\right)$ "var" ve "yok" durumları için sırasıyla 1 ve 0 alınacaktır. Görünen kalite değerlendirmesi "iyi" ise olumsuzluk parametre değeri $\left(\mathrm{O}_{\mathrm{i}}\right) 0$, "orta" ise 1 "kötü" ise 2 alınacaktır. Her bir parametreye karşı gelen olumsuzluk katsayıları Tablo 4 'te gösterilmektedir.

Tablo 4: Olumsuzluk parametre değerleri (Oi)(RBTE,2013)

\begin{tabular}{|c|c|c|c|c|c|}
\hline \multirow{2}{*}{$\begin{array}{c}\text { Olumsuzluk } \\
\text { parametre } \\
\text { no }\end{array}$} & \multirow{2}{*}{$\begin{array}{c}\text { Olumsuzluk } \\
\text { parametresi }\end{array}$} & $\begin{array}{c}\text { Parametre } \\
\text { tespiti }\end{array}$ & $\begin{array}{c}\text { Parametre } \\
\text { değeri }\end{array}$ & $\begin{array}{c}\text { Parametre } \\
\text { tespiti }\end{array}$ & $\begin{array}{c}\text { Parametre } \\
\text { değeri }\end{array}$ \\
\hline 1 & Yumuşak kat & Yok & 0 & Var & 1 \\
\hline 2 & A ğır ç1kma & Yok & 0 & Var & 1 \\
\hline 3 & Görünen kalite & Iyi & 0 & Orta (Kötü) & $1(2)$ \\
\hline 4 & K1sa kolon & Yok & 0 & Var & 1 \\
\hline 5 & Tepe/Yamaç etkisi & Yok & 0 & Var & 1 \\
\hline 6 & Planda düzensizlik & Yok & 0 & Var & 1 \\
\hline
\end{tabular}

Yapıda bulunan toplam kat adedine göre her bir olumsuzluk katsayısı olumsuzluk parametre puanı ile çarpıldıktan sonra bu değerlerin toplamı yapıdaki olumsuzlukların toplam puanı belirlenir. Olumsuzluk parametre puanlarının değerleri Tablo 5'te verilmiştir. 
Işık E. ve diğ.:Betonarme Binaların Web Tabanlı Hızlı Değerlendirilmesi

Tablo 5. Olumsuzluk parametre puan $\left(\mathrm{OP}_{\mathrm{i}}\right)$ tablosu $(\mathrm{RBTE}, 2013)$

\begin{tabular}{|c|c|c|c|c|c|c|c|c|c|c|c|}
\hline \multirow{4}{*}{$\begin{array}{l}\text { Toplam } \\
\text { kat } \\
\text { sayls1 }\end{array}$} & \multicolumn{11}{|c|}{ Olumsuzluk parametre puanları (OP) } \\
\hline & \multirow{3}{*}{$\begin{array}{c}\text { Yumuşak } \\
\text { kat }\end{array}$} & \multirow{3}{*}{$\begin{array}{l}\text { Görünen } \\
\text { kalite }\end{array}$} & \multirow{3}{*}{$\begin{array}{c}\text { AğıIr } \\
\text { çıma }\end{array}$} & \multicolumn{4}{|c|}{$\begin{array}{c}\text { Kat seviyesi/Bağımsiz bina } \\
\text { durumu }\end{array}$} & \multirow{3}{*}{$\begin{array}{l}\text { Düsseyde } \\
\text { düzensizlik }\end{array}$} & \multirow{3}{*}{$\begin{array}{c}\text { Planda } \\
\text { düzensizlik / } \\
\text { Burulma }\end{array}$} & \multirow{3}{*}{$\begin{array}{c}\text { Kisa } \\
\text { kolon }\end{array}$} & \multirow{3}{*}{$\begin{array}{l}\text { Tepe/ } \\
\text { yamaç } \\
\text { etkisi }\end{array}$} \\
\hline & & & & Ayn1 & Ayn1 & Farkl & Farklı & & & & \\
\hline & & & & Orta & Kenar & Orta & Kenar & & & & \\
\hline 1,2 & -10 & -10 & -10 & 0 & -10 & -5 & -15 & -5 & -5 & -5 & -3 \\
\hline 3 & -20 & -10 & -20 & 0 & -10 & -5 & -15 & -10 & -10 & -5 & -3 \\
\hline 4 & -30 & -15 & -30 & 0 & -10 & -5 & -15 & -15 & -10 & -5 & -3 \\
\hline 5 & -30 & -25 & -30 & 0 & -10 & -5 & -15 & -15 & -10 & -5 & -3 \\
\hline 6,7 & -30 & -30 & -30 & 0 & -10 & -5 & -15 & -15 & -10 & -5 & -3 \\
\hline
\end{tabular}

Yapı ile ilgili toplanacak veriler ile betonarme binaya ait performans puanı hesaplanacaktır. Betonarme bir bina için yapı performans puanı,

$$
P P=T P+\sum_{i=1}^{n} O_{i} * O P_{i}+Y S P
$$

ifadesi ile hesaplanacaktır. Burada, PP; performans puan1, TP; taban puan1, OP; olumsuzluk puanı, YSP ise yapısal sistem puanı olarak tarif edilmektedir.

İncelenen bölgedeki binalara yöntemin uygulanması sonucu her bir bina için performans puanı (PP) hesaplanacaktır. Hesaplanan performans puanları büyükten küçüğe doğru sıralanacaktır. Bu şekilde hesaplanan puanların dağılımı kullanılarak bölgeler arasında risk önceliği belirlenebilir.

\section{WEB TABANLI HIZLI DEĞERLENDİRME}

Web tabanlı bina performans değerlendirme sistemi için PHP tabanlı MySQL veri tabanı kullanılarak bir sayfa tasarımı gerçekleştirilmiştir. Bu yazılım, veri tabanında kayıtlı ve üzerinden çalışan bina değerlendirme ve izleme sisteminin temelini oluşturmaktadır. Uygulama temel olarak, bir arayüz ve veri tabanından oluşmaktadır. Arayüz sayesinde binaya ait Tablo 1 'de verilen bilgilerin online olarak girilmesini ve bu değerlere bağlı olarak performans puanını hesaplanmasını amaçlanmıştır. Hesaplanan performans puanı binanın bulunduğu bölgedeki diğer binaların performans puanları ile kıyaslanmıştır. Yazılımın genel çalışma algoritması Şekil 1'de sunulmuştur. Yazılım bina ekleme, performans puanı hesaplama ve analiz algoritmalarından oluşmaktadır. Geliştirilen yazılım www.smarthomescada.com/pp/ adresinden hizmet vermektedir.

Sisteme giren kullanıcı, binaya ait Tablo (2-5) deki verileri Şekil 2'de verilen alanlara uygun şekilde girmek zorundadır. Girilen veriler kayıt tuşuna basıldığında veri tabanına kayıt edilmektedir.

Kullanıcı binaya ait temel bilgilerin yanında binaya ait görsel ekleme yetkisine de sahiptir. Kullanıcı ayrıca, binaya ait daha önce girilmiş verileri de değiştirme yâda silme yetkisine sahiptir.

Çalışma ile binalara ait girilen veriler web üzerinden de takip edilebilmektedir. Bölgede bulunan binalar için girilen değerlere bağlı olarak web görünümü Şekil 3'te gösterilmiştir. Bu alanda kullanıcı binaların performans değerlerini ayrı ayrı görebilmenin yanında istediği binayı veri tabanından çıkartabilmektedir. Bu çalışmada Bitlis/Tatvan ilçesinde 13 binaya ait veri girilmiş ve risk öncelik puanları hesaplanmıştır. 


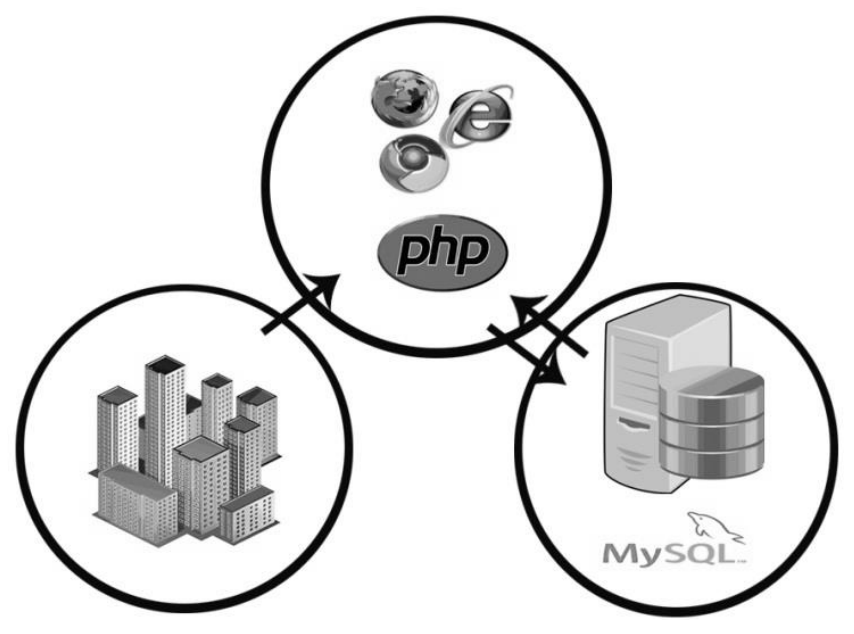

Şekil 1:

Yazılım sistemi çalışma algoritması
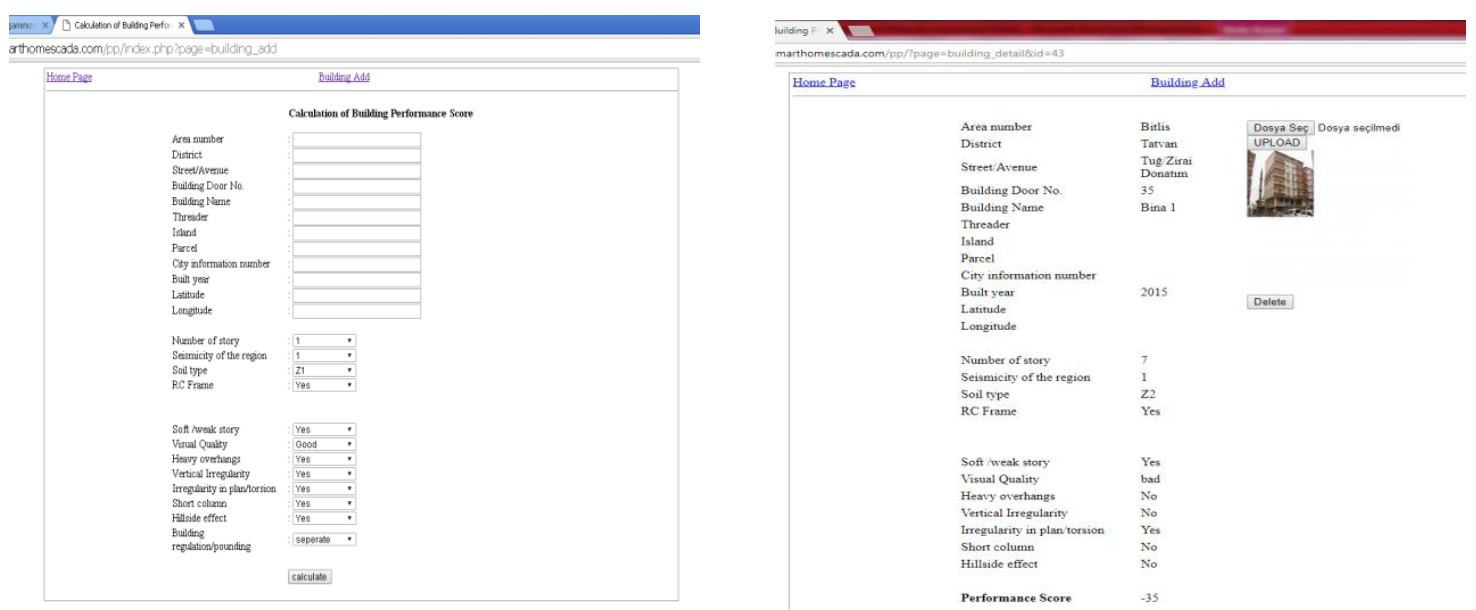

Şekil 2:

Yeni bina ekleme alanı

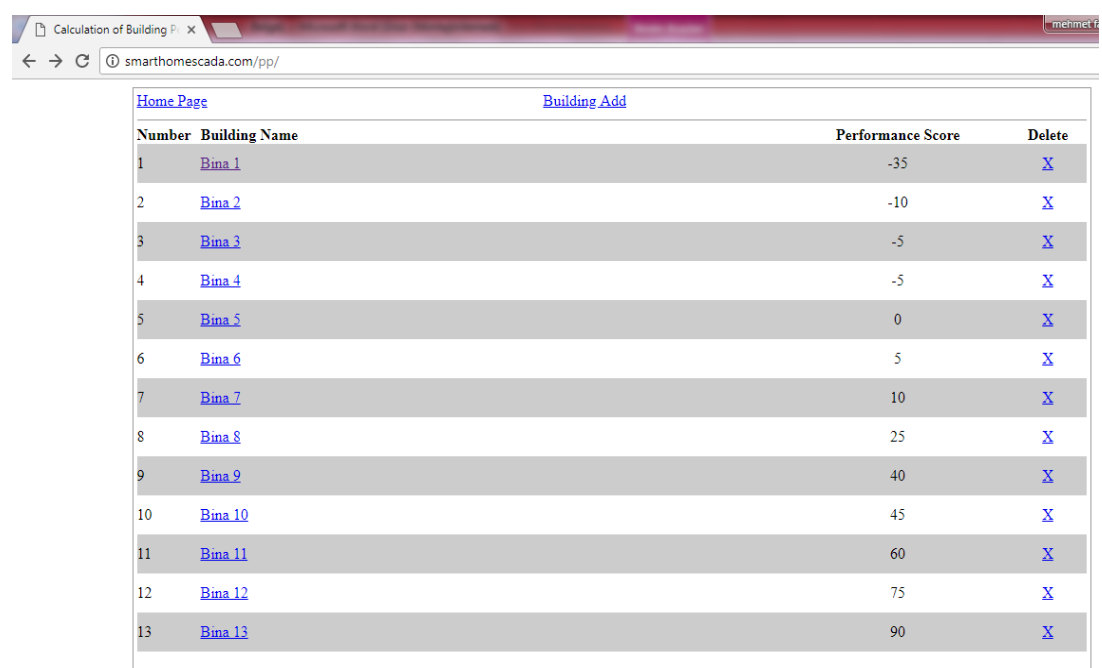

Şekil 3:

Bina hızlı değerlendirme sonuçları 
Veri tabanına kayıt edilen Bitlis/Tatvan ilçesindeki 13 binaya ait değerler Şekil 4'te gösterildiği gibi analiz amacıyla grafiksel forma dönüştürülmüştür. Grafikteki en önemli ayrıntı girilen binalara ait ortalama risk öncelik puanının belirlenmesidir. Belirlenen risk öncelik puanına göre hangi binanın puanın ortalama puanın üzerinde olduğu hangi binanın ortalamanın altında olduğu görülmektedir. Çalışmada girilen 13 binaya ait grafik incelendiğinde 4 binanın risk öncelik puanının 0 'ın altında olduğu 1 binanın 0 olduğu be 8 binanın risk öncelik puanının ise 0'ın üstünde olduğu anlaşılmaktadır. Ortalama risk öncelik puanına göre bölgedeki 0'ın üstündeki 8 binadan 5 binanın risk öncelik puanının ortalamanın üstünde olduğu anlaşılmaktadır.

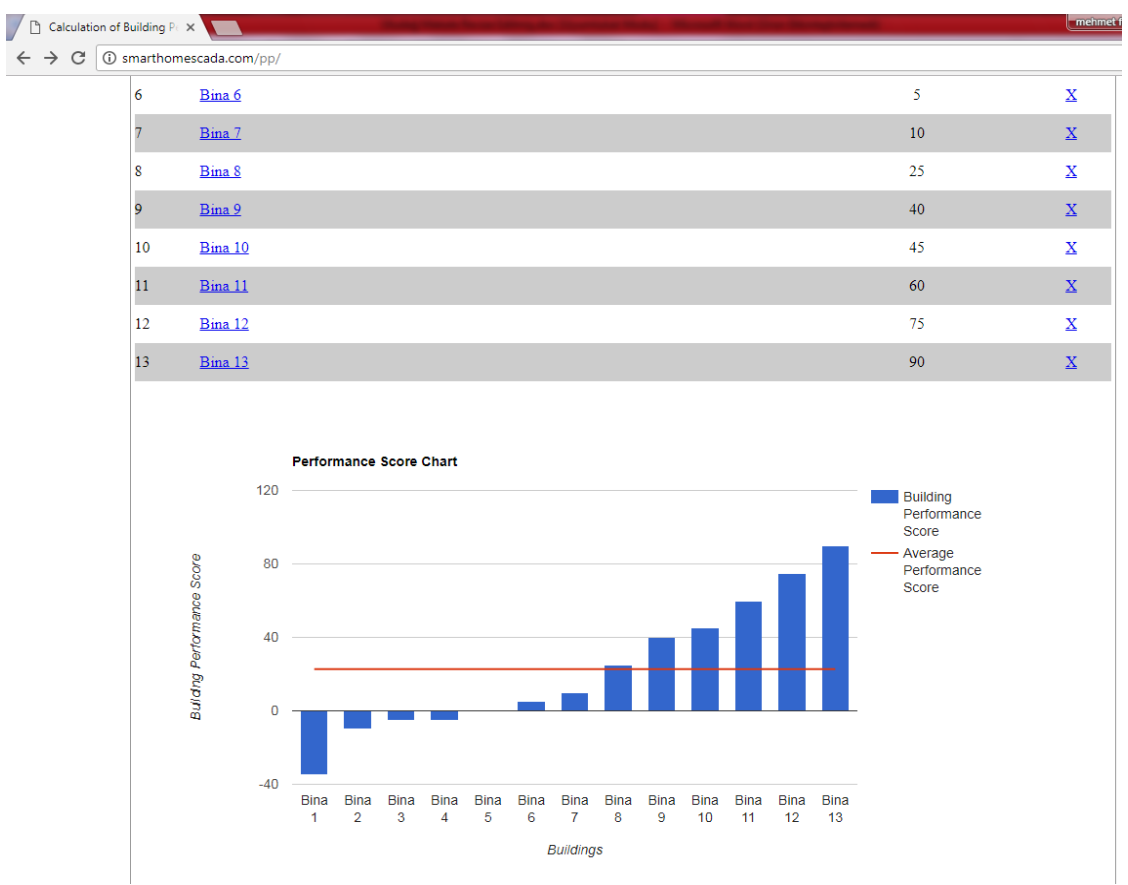

Şekil 4:

Bina değerlendirme sistemi analiz ekranı

Ayrıca yazılım içinde, veri girişi esnasında kullanıcı tarafından hatalı giriş yapılmaması amacıyla bazı alanlara sınırlama getirilirken bazı alanlara ise seçenekli giriş oluşturulmuştur. Yönetici, binaya ait parametrelerde yeniden düzenleme yapmak istediğinde yâda binaya ait bilgileri silmek istediğinde binayı seçmek kaydı ile düzenleme yapabilmektedir.

Yönetici aynı zamanda Image Uptade alanına binaya ait daha önce çekilmiş görselleri yükleyebileceği gibi akıllı telefon veya tabletiyle çekeceği fotoğrafi da veri tabanına yükleyebilmektedir.

\section{SONUÇLAR VE İLERIYYE YÖNELİK ÇALIŞMALAR}

Çalışma ile herhangi bir yerleşim biriminde yer alan betonarme yapıların envanteri elektronik ortama taşınmış ve her bir yapı için elektronik ortamda bir kimlik kartı oluşturulmuştur. Oluşturulan bu kimlik kartları farklı kurumlardan alınması veya istenmesi gereken bilgileri internet üzerinden çok hızlı çalışabilen MYSQL veri tabanında bir araya getirmiş̧ir.

$\mathrm{Bu}$ çalışma ile betonarme yapılar için elektronik bir veri tabanı oluşturmanın yanında 1-7 katlı mevcut betonarme binanın risk önceliği için kimlik kartı oluşturulması amaçlanmıştır. Elde edilen bilgilerin olası depremde meydana gelebilecek tehlikelerin etkilerinin azaltılması için kullanılması öngörülmektedir. 
Yapıların sistematik bir şekilde değerlendirilmesi ve bunun sonucu olarak oluşan zarar ve can kayıplarının belirlenmesi açısından önem arz etmektedir. Bu çalışma deprem- yapı ilişkisi ile ilgili çalıșmalarda karar destek aracı olarak kullanılabilmektedir. Çalıșmada sahadan toplanan veriler elektronik ortama entegre edilmiş ve elde edilen veriler sağlıklı, kolay ve hızlı bir şekilde paylaşılmıştır.

Olası bir depremden sonra hangi tür yapılarda ne tür hasarlar oluştuğu ve bu hasarlardan ders almak anlamında bu çalışma önemli bir yer tutacaktır. Elektronik ortama aktarılan bu veriler ile depremin şiddeti, çeşitli derecelerde hasar görmüş ve kullanılabilir bina sayıları belirlenecektir. Bunun sonucu olarak insanların esas faaliyetleri daha rahat düzenlenebilir.

Binalar ile ilgili veriler sistematik sinıflandırılarak afet yönetiminin daha iyi organize edilebilmesinin yanında binalardan oluşturulacak bu veri tabanı ile deprem bölgeleri daha gerçekçi olarak belirlenebilecektir. Bu konularda yapılacak ileri düzey çalışmalar için bir kaynak oluşturulabilecektir. Hasar gören binaların ve bunları meydana getiren yap1 elemanlarının özellikleri belirlenerek, yeni yapılacak binaların plan ve projelendirilmesinde bu bilgilerin kullanılması ile deprem tehlikesinin azaltılması sağlanabilir. Bu da mevcut deprem, projelendirme ve inşaat yönetmeliklerinin gelişimine katkı sağlayacaktır.

$\mathrm{Bu}$ çalışmayla yerel yönetimler ile ilgili kamu kurum ve kuruluşları, bina stoğu ve verilere doğrudan ulaşabilecek ve istedikleri takdirde bu verilerin elektronik ortamda kullanılabilirliklerini sağlayacaklardır.

Binaların bu şekilde elektronik izleme sistemlerine sahip olması yapılardaki numarataj işlemlerini oldukça kolaylaştıracaktır.

Binalar ile ilgili deprem sonrası veriler yardımı ile binalarda hasar belirlenmesi, bunların sınıflandırılması ve kullanım için karar verme süreci kontrollü bir şekilde yapılabilecektir.

Kurulan sistemde tüm veriler tek bir veri tabanında etkin ve ayrıntılı bir şekilde ilişkilendirilmiş olarak tanımlanabilmekte, saklanabilmekte, işlenebilmekte ve analiz edilebilmektedir. Bu sayede, karar verme ve uygulama süreçlerinde, zamandan ve mali yönden tasarruf edilebilmekte, kurumsal kaynak planlama altyapısı oluşturulabilmektedir.

Çalışmada ele alınan yöntem ile tutarlı yapı bilgi sistemi altyapısına sahip, bilgiye dayalı yönetim süreci ve bilgiye dayalı stratejik plan yapabilme etkin olarak kullanılabilecektir. Ayrıca çalışma ile edilecek yapı stoku verilerine, mekândan bağımsız olarak ulaşılabilme imkanı doğacaktır.

Çalışma yerel yönetimlerin desteği alınarak kolaylıkla yaygınlaştırılabilir. Bu çalışma yeni modüllerle genişletilebilir. Sürdürülmesi kolaylıkla sağlanabilir.

Mevcut yap1 stokunun çok olması bu tür yapılarla ilgili değerlendirmelerin zaman ve teknik eleman eksikliğinden dolayı çok gerçekçi olmadığı sonucunu ortaya çıkarmaktadır. $\mathrm{Bu}$ değerlendirmelerin bilimsel olarak sağlıklı sonuçlar verebilmesi için hızlı değerlendirme yöntemlerine ihtiyaç duyulmaktadır. Bu ihtiyaca binaen Çevre ve Şehircilik Bakanlığ tarafından riskli binaların tespit esasları belirlenmiştir. Bu tespit esaslarında yer alan değerlendirme yöntemlerinden biri de birinci aşama değerlendirme yöntemidir. Yapının deprem altındaki davranışını etkileyecek bazı parametrelerin yapı içine girmeden kısmen de yapı içerisinden elde edilen belirlenmesi mümkündür. Elde edilen parametrelerin her biri için bir puan tarif edilmekte, bu puanlar arasındaki ilişkiden faydalanılarak bina performans puanı hesaplanmaktadır. Bu hesaplama ile binalarda risk öncellikleri belirlenmektedir.

Düşük riskli çıkan binaların deprem yönetmeliğine uygun olup olmadığı kesin bir dille söylenemez. Yukarıda belirtildiği gibi bu sadece birinci aşama değerlendirmedir. Dolayısıyla kesin sonuçlar ancak kesin analiz yöntemleri sonucunda ortaya çıkacaktır. Bu yöntem sadece ikinci aşama değerlendirme yönteminde incelecek binaların önceliğinin belirlenmesi amacı taşımaktadır. 
Işık E. ve diğ.:Betonarme Binaların Web Tabanlı Hızı Değerlendirilmesi

\section{KAYNAKLAR}

1. Broeders, J., Croux, D., Peeters, M., Beyens, T., Duchateau, S., Cleij, T. J., De Ceuninck, W. (2013) Mobile application for impedance-based biomimetic sensor readout. Sensors Journal, IEEE, 13(7), 2659-2665. doi :10.1109/JSEN.2013.2256346

2. Delgado, J. A., Kowalski, K., Tebbe, C. (2013) The first Nitrogen Index app for mobile devices: Using portable technology for smart agricultural management. Computers and Electronics in Agriculture, 91, 121-123. doi: 10.1016/j.compag.2012.12.008

3. Gong, A., Wu, X., Qiu, Z., He, Y. (2013) A handheld device for leaf area measurement. Computers and Electronics in Agriculture, 98, 74-80. doi: 10.1016/j.compag.2013.07.013

4. http://www.smarthomescada.com

5. Ishigaki, Y., Matsumoto, Y., Ichimiya, R., Tanaka, K. (2013) Development of mobile radiation monitoring system utilizing smartphone and its field tests in Fukushima. Sensors Journal, IEEE, 13(10), 3520-3526. doi:10.1109/JSEN.2013.2272734

6. Iş1k, E., (2015) Investigation of an existing RC building with different rapid assessment methods. Bitlis Eren University Journal of Science and Technology, 5(2), 71-74. doi: 10.17678/beujst.42802

7. Işık, E., (2013) Bitlis ili yapı stoğunun birinci kademe ( sokak tarama yöntemi ile) değerlendirilmesi. Süleyman Demirel Üniversitesi, Fen Bilimleri Enstitüsü Dergisi, 17(1), $173-178$

8. Lee, B. G., Chung, W. Y. (2012) Driver alertness monitoring using fusion of facial features and bio-signals. Sensors Journal, IEEE, 12(7), 2416-2422. doi: 10.1109/JSEN.2012.2190505

9. Lee, J., Reyes, B. A., McManus, D. D., Mathias, O., Chon, K. H. (2013) Atrial fibrillation detection using an iPhone 4S. Biomedical Engineering, IEEE Transactions on, 60(1), 203206. doi: 10.1109/TBME.2012.2208112

10. Lehmann, R. J., Reiche, R., Schiefer, G. (2012) Future internet and the agri-food sector: State-of-the-art in literature and research. Computers and Electronics in Agriculture, 89, 158-174. doi: 10.1016/j.compag.2012.09.005

11. Sallabi, F., Fadel, M., Hussein, A., Jaffar, A., El Khatib, H. (2011) Design and implementation of an electronic mobile poultry production documentation system. Computers and Electronics in Agriculture,76(1), 28-37. DOI: doi:10.1016/j.compag.2010.12.016

12. Sucuoğlu, H. (2007) Deprem yönetmeliği performans esaslı hesap yöntemlerinin karşılıklı değerlendirmesi. Türkiye Mühendislik Haberleri, 445, 24-36.

13. Qin, C., Bao, X., Choudhury, R. R., Nelakuditi, S. (2014) Tagsense: Leveraging smartphones for automatic image tagging. Mobile Computing, IEEE Transactions on, 13(1), 61-74. doi:10.1109/TMC.2012.235.

14. Riskli Bina Tespit Esasları (RBTE, 2013) Afet Riski Altındaki Alanların Dönüştürülmesi Hakkında Kanunun Uygulama Yönetmeliğinde Değişiklik Yapılmasına Dair Yönetmelik, Çevre ve Şehircilik Bakanlığı.

15. Türk Deprem Yönetmeliği (DBYBHY 2007), Deprem Bölgelerinde Yapılacak Binalar Hakkında Yönetmelik, T. C. Çevre ve Şehircilik Bakanlığı, Afet İşleri Genel Müdürlüğü, Deprem Araştırma Dairesi. 